\title{
Changes in egg size of the diamondback moth Plutella xylostella (Lepidoptera: Yponomeutidae) treated with fenvalerate at sublethal doses and viability of the eggs
}

\author{
Yuki Fujiwara, ${ }^{1}$ Tomoko Takahashi, ${ }^{2}$ Toshie Yoshioka ${ }^{3}$ and Fusao Nakasuji*
}

Faculty of Agriculture, Okayama University, Okayama 700-8530, Japan

(Received 3 August 2001; Accepted 26 October 2001)

\begin{abstract}
Fecundity and egg size were compared in adult of the females adult diamondback moth, Plutella xylostella (Lepidoptera: Yponomeutidae) treated and untreated with sublethal doses of fenvalerate in order to understand the physiological significance of insecticidal hormoligosis. The 4 th stadium larvae were treated with fenvalerate at $\mathrm{LD}_{25}$ or $\mathrm{LD}_{50}$. More eggs were laid by treated females at $\mathrm{LD}_{25}$ than untreated females, although the difference was only marginally significant $(p=0.07)$. However, the eggs laid by treated females at $\mathrm{LD}_{25}$ and $\mathrm{LD}_{50}$ were significantly smaller in size than those laid by the control. The reproductive effort (fecundity $\times$ egg size) did not differ between treated females and the control. The treatment of a sublethal dose $\left(\mathrm{LD}_{50}\right)$ against the parent affected the development and survival of offspring at immature stages of males. The hatchability of smaller eggs laid by treated females at $\mathrm{LD}_{25}$ tended to be lower than those of controls under different humidity conditions, and the difference was apparent at a humidity of $29 \%$. The survival rate of the offspring at immature stages was lower in the treatment group $\left(\mathrm{LD}_{25}\right)$ than in the control group, and development tended to be prolonged in the former group at temperatures higher than $20^{\circ} \mathrm{C}$.
\end{abstract}

Key words: Egg size, Plutella xylostella, fenvalerate, hormoligosis, viability of offspring

\section{INTRODUCTION}

Resurgence after application of insecticides is attributed to the following processes: (a) reduction of natural enemies after pesticide use, (b) favorable influences of pesticide on phytophagous arthropods, and (c) removal of competitive species (Ripper, 1956). The second process, called physiological resurgence, is induced by two different mechanisms, tropobiosis (Chaboussou, 1966) and hormoligosis (Townsent and Luckey, 1960). Hormoligosis induced by insecticides is termed "insecticide hormoligosis" (Luckey, 1968).

Resurgence has been observed in the diamondback moth (DBM), Plutella xylostella (Lepidoptera: Yponomeutidae) (Nemoto et al., 1984; Muckenfuss et al., 1992). Sota et al. (1998) reported that the application of a carbamate, methomyl, and a pyrethroid, fenvalerate, to DBMs at sublethal doses caused hormoligosis through stimulating the reproductive potential. More eggs were laid by treated female adults than by those without insecticides at a dose of $\mathrm{LD}_{12.5}$ or $\mathrm{LD}_{25}$. However, few studies have been conducted on the physiological mechanisms of insecticide hormoligosis. For the current paper, we examined whether the increased fecundity of DBM females was due to an allocation of more nutrition to egg production or merely to partitioning of existing nutrition into more eggs. We compared the fecundity of female DBMs and egg sizes between individuals treated with fenvalerate at sublethal doses and those without treatment.

If female adults treated with insecticides lay smaller eggs and the reproductive effort does not differ between the treatment group and the untreated group, it is possible that female DBMs partition their nutrition into more eggs. Furthermore, increased fecundity may not always contribute to an upsurge in the DBM population, due to lower survival rates of offspring from smaller eggs under harsh field conditions. We also compared the via-

\footnotetext{
* To whom correspondence should be addressed.

${ }^{1}$ Present address: Tenmaya Store Co. Ltd., Okayama 702-8056, Japan

${ }^{2}$ Present address: Central Research Laboratory, Dainihon Jochugiku Co. Ltd., Toyonaka, Osaka 561-0827, Japan

${ }^{3}$ Present address: Okayama Prefectural Foundation for Environmental Conservation Enterprise, Okayama 701-0212, Japan
} 
bility of offspring between the DBM females treated with fenvalerate and without treatment under different environmental conditions.

\section{MATERIALS AND METHODS}

Insect stock culture. A strain of DBM susceptible to insecticides was obtained from a laboratory colony maintained at the Sumitomo Chemical Co., Ltd., in 1998.

About 400 adults were put into a plastic cage $(24 \times 24 \times 29.5 \mathrm{~cm})$ for egg laying. The eggs were placed in a polypropylene cage $(29 \times 18 \times 8 \mathrm{~cm})$, and the hatched larvae were fed on radish seedlings until they pupated in the same cage. The emerged adults were introduced into a plastic cage containing radish seedlings and absorbent cotton with $10 \%$ honey solution, and allowed to mate and lay eggs. The stock culture was maintained at $25^{\circ} \mathrm{C}$ under 16L8D.

Determination of insecticide susceptibility. Topical application was used to determine the insecticide susceptibility of DBMs. Various concentrations of technical-grade fenvalerate (fenvalerate racemic $[(R S)$ - $\alpha$-cyano-3-phenoxybenzyl $(R S)$-2(4-chlorophenyl)-3-methyl butyrate], $95.3 \%$ purity) were prepared with acetone. The 4th stadium larvae obtained from the stock culture were anesthetized by carbon dioxide and placed on a filter paper. A $0.5 \mu \mathrm{l}$ droplet of insecticide was applied to the dorsum with an Arnold hand Microapplicator (Burkard, U.K.). Ten larvae treated with insecticide were placed in a plastic cup $(6.5 \mathrm{~cm}$ in diameter, $4 \mathrm{~cm}$ in depth) with filter paper and a piece of cabbage leaf and maintained at $25^{\circ} \mathrm{C}$ under 16L8D. Larvae in the control plot were treated with acetone. After $24 \mathrm{~h}$, the numbers of dead or moribund larvae and surviving larvae were recorded. The data were analyzed by probit analysis (Abbott, 1925 ) with a personal computer.

Four hundred to 600 1st stadium larvae were obtained from the stock culture. They were introduced into the polypropylene cages and fed on young cabbage leaves that were grown in a greenhouse. They were reared until the 4th stadium.

The 4th stadium larvae were treated with fenvalerate at an $\mathrm{LD}_{25}$ or $\mathrm{LD}_{50}$ equivalent dose. The insects in the control plot were treated with acetone only. The surviving larvae were reared in the plastic cup and allowed to pupate. Upon emergence, a pair of male and female moths was introduced into a plastic cup with absorbent cotton with a $10 \%$ honey solution and folio sealing film (TOYOBO Co., Ltd.); a piece of cabbage leaf was inserted for oviposition stimulant. Twenty pairs were used for each treatment. The number of eggs laid on the film was observed daily until the death of the female. The sizes of ten eggs laid by each female family on the 1st, 3rd, and 5th day after emergence were measured after hatching using a video micrometer (OLYMPUS, VM-60). The major axis (a) and minor axis $(b)$ of the egg were measured, and the volume $(V)$ was calculated by the formula, $V=\pi a b^{2} / 12$, on the assumption that the shape was half ellipsoid. The hatchlings from the eggs laid by each female family on the 1 st day were introduced individually into a plastic cup with a piece of filter paper and cabbage leaf and were reared at $25^{\circ} \mathrm{C}$ under 16L8D. The developmental period and survival rate during the larval and pupal stages were recorded. The pupae were weighed on the 2 nd day of pupation. Upon emergence, a pair of female and male moths was placed in a plastic cup with absorbent cotton with $10 \%$ honey solution and folio sealing film with a cabbage leaf. The number of eggs laid was observed daily until the death of the female. The size of the eggs laid on the 1st day was measured after hatching.

Effects of a harsh environment on the viability of offspring. The humidity was adjusted to $97 \%, 79 \%, 64 \%, 43 \%$, and $29 \%$ using saturated salt solutions (Honjo, 1953) in a glass desiccator $(17 \mathrm{~cm}$ in diameter, $21 \mathrm{~cm}$ in height). The 4 th stadium larvae were treated with fenvalerate at $\mathrm{LD}_{25}$ equivalent doses or acetone. The emerged females were allowed to lay eggs on the folio sealing film with a cabbage leaf. The cabbage leaf was removed from the folio sealing film with eggs, and the film with eggs was then placed in a desiccator, and the hatchability of the eggs was observed. More than 200 eggs were used in each humidity plot and the egg size was measured after hatching.

The hatchlings from eggs laid by treated and untreated females were reared at $20^{\circ} \mathrm{C}, 25^{\circ} \mathrm{C}, 30^{\circ} \mathrm{C}$, and $33^{\circ} \mathrm{C}$ under $16 \mathrm{~L} 8 \mathrm{D}$ to investigate the effects of temperature on the development of larvae. The larvae were fed on a piece of young cabbage leaf until they pupated. The developmental period and survival rate during the larval and pupal periods were recorded. The pupae were weighed on the 2 nd day 
of pupation. More than 50 individuals were used in each plot.

\section{RESULTS}

Sublethal effects of fenvalerate on the life history traits of offspring

The $L_{25}$ and $L_{50}$ values obtained by the topical application of fenvalerate were 0.0021 and $0.0034 \mu \mathrm{g} /$ larvae. The total number of eggs laid by a female, i.e. the fecundity, and the egg sizes were compared between the sublethal dose treatment group and the untreated group (Table 1). The fecundity tended to be higher with $\mathrm{LD}_{25}$ treatment. The difference between the $\mathrm{LD}_{25}$ treatment and non-treatment control was marginally significant ( $p=0.07$, Sheffe's $F$ test). The egg size became smaller as the reproductive age of the females increased (Fig. 1). The egg sizes of the untreated controls were significantly different among the three reproductive ages $(p=0.01)$. The egg size was significantly smaller in the females treated with $\mathrm{LD}_{25}$ or $\mathrm{LD}_{50}$ than in the untreated group on both the 1 st and 3rd days (Table 1, Fig. 1). The egg size on the 5th day did not differ between the treatment group and the controls. The two-way ANOVA indicated that the variance of egg size on the 1st day was not significant $(\mathrm{df}=2, F=1.589, p=0.109)$ among the female families, although the variance among the treatment groups was highly significant $(\mathrm{df}=10, F=7.557, p=0.001)$. A statistical analysis was subsequently performed irrespective of female family. The reproductive effort was not significantly different between the treatment group and the untreated controls (Table 1).

Table 2 shows the effects of sublethal treatment of fenvalerate against the larvae in the parent on the development of offspring. The developmental period of larvae and pupae tended to be longer in the treatment group than the untreated group. The difference between the $\mathrm{LD}_{50}$ group and the controls was particularly significant only in males $(p=0.05)$. The pupal weight at $\mathrm{LD}_{50}$ tended to be lighter in the treatment group than in controls, and the difference in males was significant $(p=0.05)$.

The survival rates during the larval and pupal periods were $71.8 \%, 66.7 \%$, and $60.9 \%$ in the controls, the treatments at $\mathrm{LD}_{25}$, and those at $\mathrm{LD}_{50}$, respectively. The rates did not significantly differ between the treatment group and untreated control
Table 1. Comparison of fecundity (total number of eggs laid), egg size and reproductive effort (fecundity $X$ egg size) between females treated with fenvalerate and untreated control

\begin{tabular}{cccc}
\hline Treatment & $\begin{array}{c}\text { Fecundity } \\
(\bar{x} \pm \mathrm{SE})\end{array}$ & $\begin{array}{c}\text { Egg size } \\
\left(10^{-2} \mathrm{~mm}^{3}\right)^{\mathrm{a}} \\
(\bar{x} \pm \mathrm{SE})\end{array}$ & $\begin{array}{c}\text { Reproductive } \\
\text { effort per } \\
\text { female } \\
(\bar{x} \pm \mathrm{SE})\end{array}$ \\
\hline No treatment & $229.1 \pm 9.6 \mathrm{a}$ & $1.321 \pm 0.020 \mathrm{a}$ & $2.911 \pm 0.223 \mathrm{a}$ \\
$\mathrm{LD}_{25}$ & $263.4 \pm 9.3 \mathrm{a}$ & $1.238 \pm 0.020 \mathrm{~b}$ & $3.217 \pm 0.108 \mathrm{a}$ \\
$\mathrm{LD}_{50}$ & $223.8 \pm 9.4 \mathrm{a}$ & $1.194 \pm 0.023 \mathrm{~b}$ & $2.753 \pm 0.175 \mathrm{a}$
\end{tabular}

Means within a row followed by different letters are significantly different ( $p=0.05$, Scheffe's $F$ test).

${ }^{\text {a }}$ On the 1st day of reproductive age.

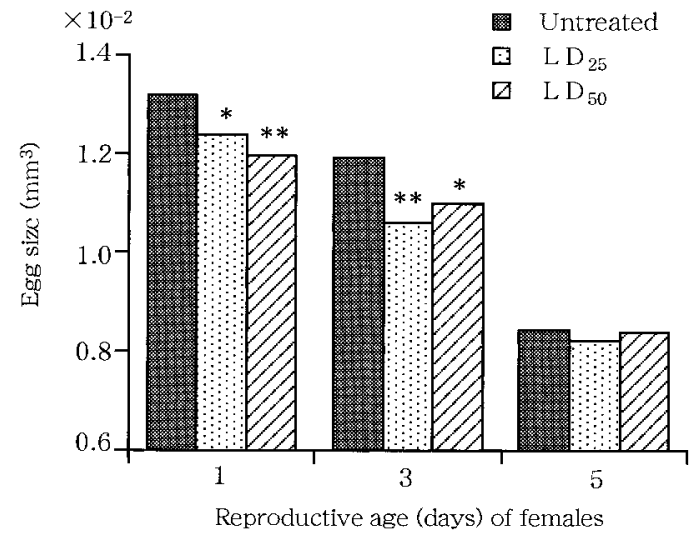

Fig. 1. Changes in the size of eggs laid by females treated with fenvalerate and those of the untreated control group. Egg size was compared between the treatment group and untreated controls within each reproductive age $(* p=0.05, * * p=0.01$, Scheffe's $F$ test).

group ( $p>0.05$, Fisher's exact probability test); however, they tended to be lower in the treatment group.

The fecundity of the emerged female adults and their egg size were not significantly different between the treatment group and the untreated controls (data not shown).

\section{Effects of a harsh environment on the viability of offspring}

Hatchability was compared between eggs laid by the females treated with fenvalerate at $\mathrm{LD}_{25}$ and by the untreated females under different humidity conditions (Fig. 2). The egg size was significantly smaller in the treatment group $\left(1.26 \times 10^{-2} \mathrm{~mm}^{3}\right.$ in average) than in the untreated group $\left(1.32 \times 10^{-2}\right.$ 
Table 2. Effects of sublethal dose treatment of fenvalerate against the parent on the development of offspring

\begin{tabular}{|c|c|c|c|c|}
\hline \multirow{2}{*}{ Treatment } & \multicolumn{2}{|c|}{$\begin{array}{l}\text { Developmental period of larvae } \\
\text { and pupae (days) }\end{array}$} & \multicolumn{2}{|c|}{ Pupal weight (mg) } \\
\hline & $\begin{array}{l}\text { Female } \\
(\bar{x} \pm \mathrm{SE})\end{array}$ & $\begin{array}{c}\text { Male } \\
(\bar{x} \pm \mathrm{SE})\end{array}$ & $\begin{array}{l}\text { Female } \\
(\bar{x} \pm \mathrm{SE})\end{array}$ & $\begin{array}{c}\text { Male } \\
(\bar{x} \pm \mathrm{SE})\end{array}$ \\
\hline No treatment & $10.69 \pm 0.13 \mathrm{a}$ & $10.59 \pm 0.15 \mathrm{a}$ & $5.97 \pm 0.12 \mathrm{a}$ & $4.61 \pm 0.08 \mathrm{a}$ \\
\hline $\mathrm{LD}_{25}$ & $10.83 \pm 0.19 a$ & $11.05 \pm 0.24 \mathrm{ab}$ & $5.99 \pm 0.13 \mathrm{a}$ & $4.65 \pm 0.09 \mathrm{ab}$ \\
\hline $\mathrm{LD}_{50}$ & $11.12 \pm 0.19 \mathrm{a}$ & $11.41 \pm 0.24 \mathrm{~b}$ & $5.63 \pm 0.14 \mathrm{a}$ & $4.28 \pm 0.11 b$ \\
\hline
\end{tabular}

Means within a row followed by different letters are significantly different ( $p=0.05$, Scheffe's $F$ test).

$\left.\mathrm{mm}^{3}\right)(p=0.05$, Mann-Whitney $U$-test $)$. Hatchability tended to be lower in eggs of the treatment group than in those from the controls, except under $63 \%$ humidity. The difference was particularly significant under $29 \%$ ( $p=0.05$, Fisher's exact probability test).

The survival rates during the larval period at different temperatures were compared between individuals produced by a parent treated with fenvalerate at $\mathrm{LD}_{25}$ and by an untreated parent (Fig. 3). The size of eggs from which larvae hatched was significantly smaller in the treatment group $\left(1.32 \times 10^{-2}\right.$ $\mathrm{mm}^{3}$ in average) than in controls $\left(1.39 \times 10^{-2} \mathrm{~mm}^{3}\right)$ ( $p=0.05$, Mann-Whitney $U$-test). The survival rate was significantly lower in the treatment group than in controls except at $20^{\circ} \mathrm{C}(p=0.05$, Fisher's exact probability test). The survival rate at $33^{\circ} \mathrm{C}$ was considerably lower than at other temperatures, and the difference between the treated and untreated groups was amplified at $33^{\circ} \mathrm{C}$. The developmental periods of the larvae and pupae and the pupal weights were compared between individuals produced by treated and untreated parents (Table 3). The developmental period tended to be prolonged in the treatment group, except at $20^{\circ} \mathrm{C}$. The difference between the treatment group and controls was significant in males at $25^{\circ} \mathrm{C}$ and $30^{\circ} \mathrm{C}$. The pupal weight did not differ between the treatment group and untreated group regardless of temperature and sex.

\section{DISCUSSION}

Insecticide hormoligosis is known to occur in some insects and mites, e.g., Sitophilus granarius (Kuenen, 1958), Tetranychus urticae (Dittrich et al., 1974), Diabrotica virgifera (Ball and Su,

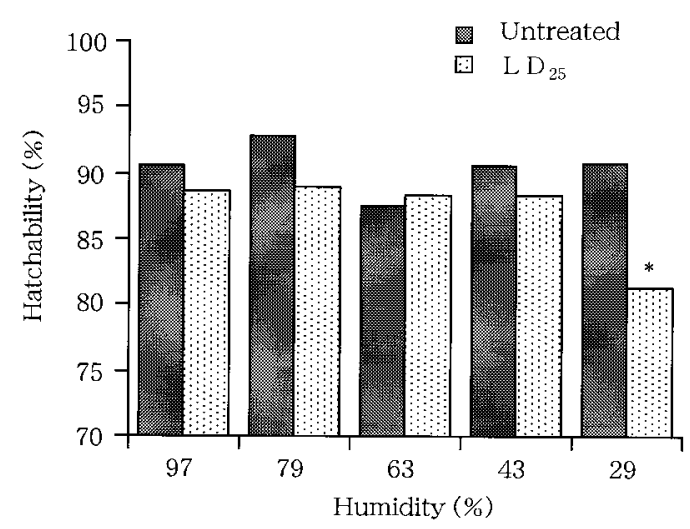

Fig. 2. Comparison of hatchability between eggs laid by females treated with fenvalerate at $\mathrm{LD}_{25}$ and by untreated females under different humidity conditions. * Significantly different between the treatment group and untreated control group ( $p=0.05$, Fisher's exact probability test).

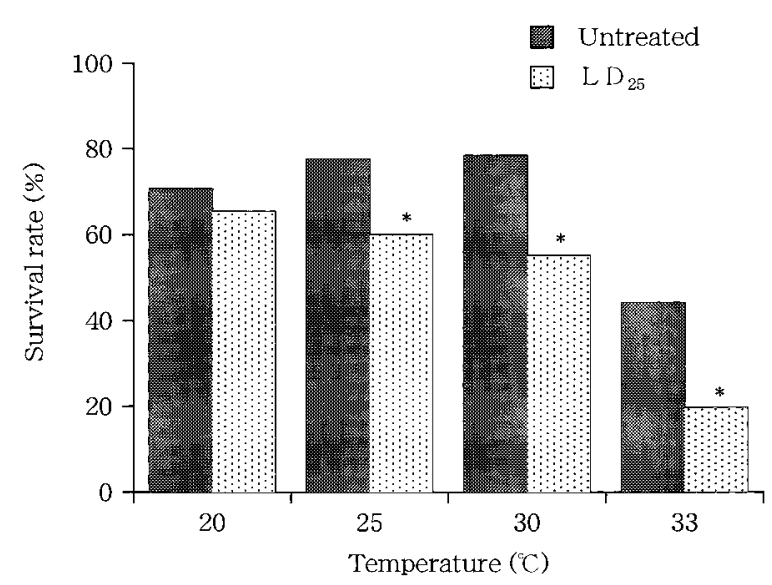

Fig. 3. Comparison of survival rate during larval and pupal periods between individuals produced by a parent treated with fenvalerate at $\mathrm{LD}_{25}$ and an untreated parent under different temperature conditions. * Significantly different between the treatment group and untreated control group ( $p=0.05$, Fisher's exact probability test). 
Table 3. Comparison of developmental period of larvae and pupae, and pupal weight between individuals produced by the parent treated with fenvalerate at the $\mathrm{LD}_{25}$ and the untreated parent under different temperature conditions

\begin{tabular}{|c|c|c|c|c|c|}
\hline \multirow{2}{*}{ Temperature } & \multirow{2}{*}{ Treatment } & \multicolumn{2}{|c|}{$\begin{array}{l}\text { Developmental period of larvae } \\
\text { and pupae (days) }\end{array}$} & \multicolumn{2}{|c|}{ Pupal weight (mg) } \\
\hline & & $\begin{array}{l}\text { Female } \\
(\bar{x} \pm \mathrm{SE})\end{array}$ & $\begin{array}{c}\text { Male } \\
(\bar{x} \pm \mathrm{SE})\end{array}$ & $\begin{array}{l}\text { Female } \\
(\bar{x} \pm \mathrm{SE})\end{array}$ & $\begin{array}{c}\text { Male } \\
(\bar{x} \pm \text { SE })\end{array}$ \\
\hline \multirow{2}{*}{$20^{\circ} \mathrm{C}$} & No treatment & $19.4 \pm 0.5$ & $19.2 \pm 0.9$ & $5.6 \pm 0.2$ & $4.7 \pm 0.1$ \\
\hline & $\mathrm{LD}_{25}$ & $19.3 \pm 0.4$ & $18.8 \pm 0.2$ & $5.5 \pm 0.2$ & $4.6 \pm 0.1$ \\
\hline \multirow[t]{2}{*}{$25^{\circ} \mathrm{C}$} & No treatment & $11.0 \pm 0.1$ & $11.1 \pm 0.1$ & $5.8 \pm 0.1$ & $4.6 \pm 0.2$ \\
\hline & $\mathrm{LD}_{25}$ & $11.1 \pm 0.1$ & $11.6 \pm 0.2^{*}$ & $5.9 \pm 0.2$ & $4.7 \pm 0.1$ \\
\hline \multirow[t]{2}{*}{$30^{\circ} \mathrm{C}$} & No treatment & $9.3 \pm 0.2$ & $9.5 \pm 0.2$ & $4.9 \pm 0.1$ & $4.1 \pm 0.1$ \\
\hline & $\mathrm{LD}_{25}$ & $9.6 \pm 0.2$ & $10.1 \pm 0.1^{*}$ & $5.2 \pm 0.2$ & $4.3 \pm 0.1$ \\
\hline \multirow[t]{2}{*}{$33^{\circ} \mathrm{C}$} & No treatment & $10.4 \pm 0.3$ & $10.4 \pm 0.3$ & $4.0 \pm 0.2$ & $3.2 \pm 0.2$ \\
\hline & $\mathrm{LD}_{25}$ & $11.3 \pm 0.3$ & $11.7 \pm 0.3$ & $3.7 \pm 0.1$ & $3.2 \pm 0.1$ \\
\hline
\end{tabular}

* Significantly different between the treatment and no treatment control ( $p=0.05$, Scheffe's $F$ test).

1979), Manduca sexta (Stewart and Philogene, 1983), Panonychus citri (Jones and Parrella, 1984), and Myzus persicae (Lowery and Sears, 1986; Ferguson and Chapman, 1992). The phenomenon was particularly prominent in the brown planthopper Nilaparvata lugens (Chelliah et al., 1980) and the DBM (Nemoto et al., 1984). These two studies involved topical application of insecticides to nymphs or larvae.

Sota et al. (1998) recently reported that fecundity in the DBM increased significantly when treated with sublethal doses of fenvalerate. In this study, the fecundity of DBM females also increased when the larvae were treated with fenvalerate at $\mathrm{LD}_{25}$, although the difference from that of untreated females was only marginally significant $(p=0.07)$. The application of fenvalerate at sublethal doses apparently causes insecticide hormoligosis in DBMs. We also found that the DBM females treated with fenvalerate lay smaller eggs, indicating an egg size/egg-number trade-off. Consequently, the reproductive effort did not differ between treated and untreated females. This evidence indicates that the DBM female allocates a specific amount of nutrition into more eggs of smaller size under hormoligosis conditions.

Some insects alter their egg size under different environments. For example, female adults of a migrant skipper Parnara guttata lay different-sized eggs under different photoperiod regimens (Nakasuji and Kimura, 1984). The egg size variation of the skipper is associated with the leaf toughness of larval host plants (Nakasuji, 1987). A seed beetle, Stator limbatus, lays different-sized eggs on seeds of host plants with different qualities (Fox and Mousseau, 1996). However, no evidence has been reported regarding changes in egg size by a chemical stimulant. Roan and Hopkins (1961) reported that the excitation of the nervous system by an insecticide initiates a chain of events, beginning with the release of neuroendocrine secretions, which, in turn, induce responses in target organs. Two oocytes of female Panonychus ulmi matured simultaneously when the females were kept on DDT residues, while only one oocyte matured in the control females (Seifert, 1961). Sublethal effects of insecticides on behavior and reproduction were reviewed by Haynes (1988). However, the mechanisms of reproductive stimulation through sublethal effects have not been studied in regard to egg size variation.

In general, a larger insect egg results in a higher viability in subsequent developmental stages (Capinera et al., 1977; Rossitor, 1991; Brady, 1994; Fox, 1997). However, some studies have demonstrated that the egg size does not affect survival (e.g. Harvey, 1977; Wiklund and Persson, 1983). Larger eggs and the larvae hatched from them may 
exhibit a higher viability particularly under harsh environmental conditions. This was true in the case of DBMs.

Outbreaks of DBMs occur frequently after application of some insecticides, and the outbreaks appear to be caused by hormoligosis (Nemoto et al., 1984; Sota et al., 1998) as well as by decimation of natural enemies (Nemoto, 1993). The treatment of fenvalerate at sublethal doses produces DBM females that lay more but smaller-sized eggs. The lower viability of the smaller eggs and the larvae from the smaller eggs may cause a lower reproductive rate even though the fecundity of the females is high. Therefore, it is doubtful that the outbreaks occur through insecticide hormoligosis under harsh field conditions, e.g. high temperatures (Shirai, 2000). Intensive studies are needed on the causative factors that influence the resurgence of DBMs in fields.

\section{ACKNOWLEDGEMENTS}

We thank Professor K. Fujisaki, Dr. T. Miyatake, Ms. R. Tsukuda and Mr. T. Irie, Faculty of Agriculture, Okayama University, and Ms. N. Sota, National Food Research Institute, Tsukuba, for their assistance throughout this work. Thanks are also due to Sumitomo Chemical Co. Ltd. for providing the susceptible strain of the DBM and technical grade fenvalerate.

\section{REFERENCES}

Abbott, W. S. (1925) A method of computing the effectiveness of an insecticide. J. Econ. Entomol. 18: 265-267.

Ball, H. J. and P. P. Su (1979) Effect of sublethal dosages of carbofuran and carbaryl on fecundity and longevity of the female western corn rootworm. J. Econ. Entomol. 72: 873-876.

Brady, M. F. (1994) The significance of egg size variation in butterflies in relation to host plant quality. Oikos 71: 119129.

Capinera, J. L., P. Barbosa and J. H. Hegedorn (1977) Yolk and yolk depletion of gypsy moth eggs: implication for population quality. Ann. Entomol. Soc. Am. 70: 40-42.

Chaboussou, F. (1966) Nouveaux aspects de la phytiatrie et la phytopharmacie. Le phenomene de la trophobiose. Proc. FAO Symp. Integ. Pest. Control, Rome 1: 33-61.

Chelliah, S., L. T. Fabellar and E. A. Heinrichs (1980) Effect of sub-lethal doses of three insecticides on the reproductive rate of the brown planthopper, Nilaparvata lugens, on rice. Environ. Entomol. 9: 778-780.

Dittrich, V., P. Streibert and P. A. Bathe (1974) An old case reopened: mite stimulation by insecticide residues. Environ. Entomol. 3: 534-540.

Ferguson, J. S. and R. K. Chapman (1992) Factors involved in carbaryl-induced population buildups of Myzus persicae (Sulzer) (Homoptera: Aphididae) on potato. J. Agric. Entomol. 10: 51-64.
Fox, C. W. (1997) Egg-size manipulation in the seed beetle Stator limbatus: consequences for progeny growth. Can. J. Zool. 75: 1465-1473.

Fox, C. W. and T. A. Mousseau (1996) Larval host plant affects the fitness consequence of egg size in the seed beetle Stator limbatus. Oecologia 107: 541-548.

Harvey, G. T. (1977) Mean weight and rearing performance of successive egg clusters of eastern spruce budworm (Lepidoptera; Tortricidae). Can. Entomol. 109: 487-496.

Haynes, K. F. (1988) Sublethal effects of neurotoxic insecticides on insect behavior. Ann. Rev. Entomol. 33: 149168.

Honjo, I. ed. (1953) Biology Handbook. Iwanami, Tokyo. 250 pp. (in Japanese).

Jones, V. P. and M. P. Parrella (1984) The sublethal effects of selected insecticides on life table parameters of Panonychus citri (Acari: Tetranychidae). Can. Entomol. 116: 1033-1040.

Kuenen, D. J. (1958) Influence of sublethal doses of DDT upon the multiplication of Sitophilus granarius (Coleopt. Curculionidae). Entomol. Exp. Appl. 1: 147-152.

Lowery, D. T. and M. K. Sears (1986) Effect of exposure to the insecticide azinphosmethyl on reproduction of green peach aphid (Homoptera: Aphididae). J. Econ. Entomol. 79: $1534-1538$.

Luckey, T. D. (1968) Insecticide hormoligosis. J. Econ. Entomol. 61: 7-12.

Muckenfuss, A. E., B. M. Shepard and E. R. Ferrer (1992) Natural mortality of diamondback moth in Coastal South Carolina. In Diamondback Moth and Other Crucifer Pests, Proc. of the Second International Workshop (N. S. Talekar ed.). AVRDC, Tainan, Taiwan, pp. 27-36.

Nakasuji, F. (1987) Egg size of skippers (Lepidoptera: Hesperiidae) in relation to their host specificity and to leaf toughness of host plants. Ecol. Res. 2: 175-183.

Nakasuji, F. and M. Kimura (1984) Seasonal polymorphism of egg size in a migrant skipper, Parnara guttata guttata (Lepidoptera: Hesperiidae). Kontyu, Tokyo 52: 253-259.

Nemoto, H. (1993) Mechanism of resurgence of the diamondback moth, Plutella xylostella (L.) (Lepidoptera: Yponomeutidae). JARQ 27: 27-32.

Nemoto, H., K. Kiritani and H. Ono (1984) Enhancement of the intrinsic rate of natural increase induced by the treatment of the diamondback moth (Plutella xylostella (L.)) with sublethal concentrations of methomyl. Jpn. J. Appl. Entomol. Zool. 28: 150-155 (in Japanese with English summary).

Ripper, W. E. (1956) Effect of pesticides on balance of arthropod populations. Ann. Rev. Entomol. 1: 403-438.

Roan, C. C. and T. L. Hopkins (1961) Mode of action of insecticides. Ann. Rev. Entomol. 6: 333-346.

Rossitor, M. C. (1991) Maternal effects generate variation in life history: consequences of egg weight plasticity in the gypsy moth. Funct. Ecol. 5: 386-393.

Seifert, G. (1961) Der einfluss von DDT auf die eiproduktion von Metatetranychus ulmi Koch (Acari, Tetranychidae). Z. Angew. Zool. 29: 441-452.

Shirai, Y. (2000) Temperature tolerance of the diamondback moth, Plutella xylostella (Lepidoptera: Yponomeutidae) 
in tropical and temperate regions of Asia. Bull. Entomol. Res. 90: 357-364.

Sota, N., N. Motoyama, K. Fujisaki and F. Nakasuji (1998) Possible amplification of insecticide hormoligosis from resistance in the diamondback moth, Plutella xylostella (Lepidoptera: Yponomeutidae). Appl. Entomol. Zool. 33: 435-440.

Stewart, J. G. and B. J. R. Philogene (1983) Sublethal effects of fenitrothion on the development of a parental generation of Manduca sexta. Entomol. Exp. Appl. 33: 315-319.

Townsent, J. F. and T. D. Luckey (1960) Hormoligosis in pharmacology. J. Am. Med. Assoc. 173: 44-48.

Wiklund, C. and A. Persson (1983) Fecundity, and the relation of egg weight variation to offspring fitness in the speckled wood butterfly Pararge aegeria, or why don't butterfly female lay more eggs? Oikos 40: 53-63. 